\title{
Graphene Functionalization by 1,6-Diaminohexane and Silver Nanoparticles for Water Disinfection
}

\author{
Abdelsattar O. E. Abdelhalim, ${ }^{1}$ Ahmed Galal, ${ }^{2}$ \\ Mohamed Z. Hussein, ${ }^{1}$ and Ibrahim E.-T. El Sayed ${ }^{3}$ \\ ${ }^{1}$ Environmental Research Department, National Center for Social and Criminological Research (NCSCR), Giza 11561, Egypt \\ ${ }^{2}$ Chemistry Department, Faculty of Science, Cairo University, Giza 12613, Egypt \\ ${ }^{3}$ Chemistry Department, Faculty of Science, Menoufia University, Shebeen El-Kom, Menofia 32511, Egypt \\ Correspondence should be addressed to Ahmed Galal; galal@sci.cu.edu.eg
}

Received 28 September 2015; Revised 21 November 2015; Accepted 30 November 2015

Academic Editor: Bo Zhang

Copyright ( 2016 Abdelsattar O. E. Abdelhalim et al. This is an open access article distributed under the Creative Commons Attribution License, which permits unrestricted use, distribution, and reproduction in any medium, provided the original work is properly cited.

\begin{abstract}
Reduced graphene $(\mathrm{G})$ was prepared by chemically reducing graphene oxide (GO). For the first time, the resulting $G$ was functionalized by 1,6-diaminohexane and decorated with silver nanoparticles (AgNPs). The resulting $G$ and modified $G$ were characterized by X-ray diffraction (XRD), nuclear magnetic resonance (NMR), infrared (FTIR) spectroscopies, and high resolution transmission electron microscopy (HRTEM). The 1,6-diaminohexane-graphene structure was ascertained from the NMR and FTIR data. AgNPs were identified with various sizes within the graphene matrix. The resulting hybrid material was used as an effective antimicrobial contact catalyst for disinfecting water from Total Coliform and Fecal Coliform bacteria. A triple action in this respect was achieved from graphene, 1,6-diaminohexane, and AgNPs without observed release of silver that causes toxicity.
\end{abstract}

\section{Introduction}

Several approaches have been introduced for water disinfection [1-3]. For example, free chlorine has been the choice for water disinfection that is known to have a carcinogenic effect. Also ultraviolet or ozone were other choices; however they are relatively expensive. Nanotechnology has recently introduced several materials that include carbon-based structures such as carbon nanotubes and graphene. These materials allowed advancements in several applications including electronic, coatings, and pharmaceutical industries. In particular carbon-based structures possess unique properties such as large surface area, allowance for chemical functionalization, and well-known ability to counter microbial disinfection and removal of toxic organic pollutant suggested their application in water purification.

Graphene has unique structural properties in the form of one atomic layer of aromatic stacked structure of $\mathrm{sp}^{2}$ hybrid carbon atoms [4]. Graphene was first introduced as a "free" standing two-dimensional structure by Novoselov and his coworkers when isolated from graphite using a "scotch" tape [5]. Another advantage is the possibility of graphene using noncovalent or covalent approaches $[6,7]$. Graphene can be modified using nanostructured metallic or polymeric materials to form hybrids or composites with more advantageous properties.

For instance, silver nanoparticles have been known to have tremendous antibacterial activities with noticeable effect over other materials [8-10]. Therefore silver is known to be an effective biocide to fight several bacteria, fungi, and viruses [11]. Silver nanoparticles were therefore the focus of several investigations for their usage as antiseptic, disinfectant, and other active ingredients in pharmaceutical formulations [1214]. It was cited in the literature that the size of silver nanoparticles is among the crucial factors on their antibacterial activity. Thus, it was mentioned that silver nanoparticles with sizes $<10 \mathrm{~nm}$ proved to have relatively higher antibacterial activity because of the increase in surface area and ease of cell penetration $[10,11]$. This explained the long time usage of silver as antibacterial agents $[15,16]$. 
The mechanism of silver antibacterial function is based on its ability to release silver ions which causes inactivation to microorganism cells that is due to cell membrane destruction [17, 18]. Moreover, silver nanoparticles penetrate cell membranes causing their damage and resulting in their death $[10,19]$.

Graphene oxide (GO) is formed of stacked sheets with rich oxygen-functional groups including hydroxyl, epoxide, carbonyl, and carboxyl groups [20, 21]. Therefore, cell membranes of the bacteria are damaged when placed in contact with the oxygenated graphene walls. An example given in the literature is Escherichia coli bacteria that proved to be inhibited by GO [22]. The outstanding specific surface area of the graphene $\left(2600 \mathrm{~m}^{2} / \mathrm{g}\right)$ and the ease of its functionalization allowed its use as a substrate to form graphene composites $[20,23-25]$. Pt, Au, and Ag have also been cited in the literature to form inorganic hybrids with graphene and found good application in different domains including catalysis, sensors, and electronic [26-29].

Graphene has been also suggested for various applications in next generation storage and electronic devices [30-33]. Graphene can be prepared using chemical vapor deposition (CVD) from methane [23, 34, 35], graphite oxidation and reduction [36,37], one-step graphite exfoliation [38], graphite stamping [39], and carbon nanotube unzipping [40, 41]. Due to the ease of preparation and cost reduction, graphene has been prepared by the oxidation of graphite and then its further reduction. GO can be reduced by either chemical, thermal, or ultraviolet assisted reduction methods, respectively [42-47]. In the chemical reduction method GO in solution with large amount is converted into graphene sheets (GS) by the removal of epoxide groups present in the basal plane of GO using hydrazine as an oxidizing agent [48].

In this work, we prepared graphene by chemical reduction of graphene oxide. The resulting graphene was functionalized with 1,6-diaminohexane and further modified by silver nanoparticles. The new hybrid material was tested for the first time for its antibacterial efficiency against Total Coliform and Fecal Coliform bacteria for disinfecting wastewater of very infected water resources.

\section{Materials and Methods}

2.1. Materials. Graphite powder, sodium nitrate (99.9\%), potassium permanganate, sulfuric acid, hydrochloric acid, hydrogen peroxide $(30 \%)$, hydrazine hydrate, silver nitrate, and 1,6-diaminohexane were of analytical grade and were all purchased from Sigma-Aldrich. All chemicals were used as received without further purification.

2.2. Instrumentation. A Siemens D 5000 X-ray powder diffractometer was used for XRD analyses. The functional groups were identified by a Bruker Avance III HD proton nuclear magnetic resonance where $\mathrm{CDCl}_{3}$ was the solvent. IR spectroscopy was done with a JASCO FT/IR-4000 where the samples were in the form of a $\mathrm{KBr}$ pellet.

The morphologies of the resulting graphene and hybrids were determined using high resolution transmission electron microscopy (HRTEM) using an JEOL JEM-2100F field emission electron microscope with accelerating voltage of $200 \mathrm{kV}$. The sample for HRTEM characterization was prepared by placing a drop of colloidal solution of the sample dissolved in deionized water over a carbon-coated copper grid.

\subsection{Hybrid Graphene-1,6-Diaminohexane-Silver Nanoparticles Synthesis}

2.3.1. Graphene Oxide Preparation. Graphene oxide was prepared using a modified Hummers and Offeman method [49]. In summary, the steps were as follows: $2 \mathrm{~g}$ of graphite powder was added to $300 \mathrm{~mL}$ concentrated sulfuric acid in an ice bath. Solid $\mathrm{KMnO}_{4}(20 \mathrm{~g})$ was then added slowly and followed by the addition of $\mathrm{NaNO}_{3}(3 \mathrm{~g})$ slowly with stirring and keeping the temperature of the reaction mixture near zero. The temperature of the reaction mixture was kept at $35^{\circ} \mathrm{C}$ for 30 minutes and then $300 \mathrm{~mL}$ deionized water was added gradually with small portions and the temperature was increased to $98^{\circ} \mathrm{C}$ for 40 minutes. Then, $500 \mathrm{~mL}$ of deionized water was added to the reaction mixture followed by addition of $20 \mathrm{~mL} 30 \% \mathrm{H}_{2} \mathrm{O}_{2}$ solution.

The solid product was separated by filtration, washed repeatedly by $5 \% \mathrm{HCl}$ solution to remove sulfate ions, and then washed several times by distilled water until chloride ions are removed when the $\mathrm{pH}$ becomes neutral. The residue was kept to dry in air oven at $60^{\circ} \mathrm{C}$ for 3 hours and then redispersed in distilled water under ultrasonication for 1 hour to be exfoliated. Reddish brown nanosheets of graphene oxide (GO) in homogeneous suspension solution were obtained.

2.3.2. Conversion of $G O$ to Reduced Graphene (G). $0.5 \mathrm{~g}$ of graphene oxide sheets is dissolved in $3 \mathrm{~mL} \mathrm{H}_{2} \mathrm{O}$; then $1 \mathrm{~mL}$ of hydrazine hydrate is added to the solution and stirred for 1 hour at room temperature and then heated to $100^{\circ} \mathrm{C}$ for 2 hours, then raising the temperature to $200^{\circ} \mathrm{C}$ for $30 \mathrm{~min}$.

\subsubsection{Graphene Functionalization with 1,6-Diaminohexane} and Silver Nanoparticles. $20 \mathrm{~mL}$ of distilled water solution is added to $0.2 \mathrm{~g}$ graphene sheets with $2 \mathrm{~mL} \mathrm{HCl} 30 \%$ solution. $15 \mathrm{~mL} g$ of 1,6-diaminohexane is added with continuous stirring for 1 hour at $80^{\circ} \mathrm{C}$. $10 \mathrm{~mL} \mathrm{AgNO}_{3} 10 \%$ is added followed by $3 \mathrm{~mL}$ hydrazine hydrate with continuous stirring at room temperature for $15 \mathrm{~min}$ and left overnight at room temperature. The precipitate is removed by centrifugation.

\subsection{Testing for Coliform and Fecal Coliform. Appropriate} sampling container was used and sterilized with sodium thiosulfate to remove chlorine. The sample was a representative one and was collected at a sewage water dump nearby Nile Delta in Egypt. After collection the sample was refrigerated and delivered to the Nile Research Institute at the National Water Research Center of Egypt to carry the tests within 2 hours after collection.

Fecal Coliform tests were conducted according to SM 9222D guidelines using M-FC broth (with 96-hour shelve life). The samples were incubated at $44.5 \pm 0.2^{\circ} \mathrm{C}$ for $24 \pm 2$ 


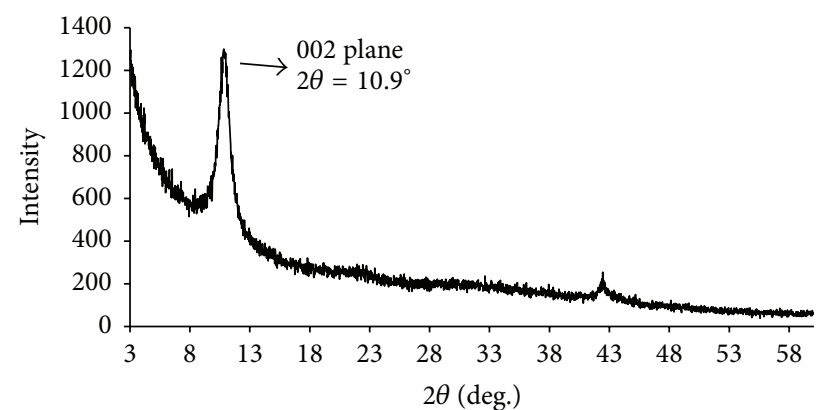

FIGURE 1: XRD pattern of graphene oxide.

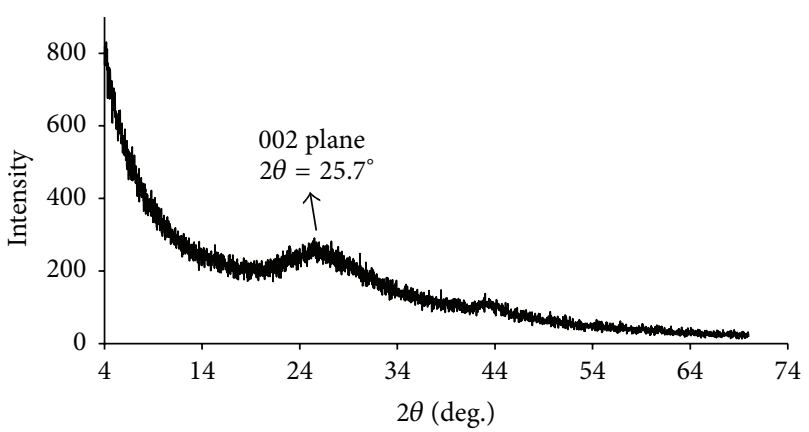

FIGURE 2: XRD pattern of graphene.

hours and the blue colonies were counted for four sample dilutions.

For Total Coliform, SM 9221B guidelines were adopted using multiple-tube fermentation technique. In this procedure, LTB presumptive medium was incubated at $35 \pm 0.5^{\circ} \mathrm{C}$ for $24 \pm 2$ hours. Brilliant green lactose bile broth was used at $35 \pm 0.5^{\circ} \mathrm{C}$ for $24 \pm 2$ hours. Results were calculated using SM table 9221(IV). For all tests, control cultures were used for the microbiological tests.

\section{Results and Discussion}

3.1. Characterization of Graphene Oxide (GO) and Graphene $(G)$. The structure of the prepared GO was ascertained using XRD and FT-IR. Figure 1 shows the XRD pattern of GO where a characteristic peak (002 plane) appears at 2 theta $=$ $10.9^{\circ}$ indicating the presence of oxygen containing functional groups after liquid phase oxidation. Figure 2 shows the XRD pattern of graphene formed by chemical reduction of GO. The XRD results of Figure 2 proved the disappearance of both the peak related to $\mathrm{GO}$ (around $10^{\circ}$ ) and that related to graphite $\left(26^{\circ}\right)$. However, the XRD pattern of graphene is characterized by a characteristic peak ( 002 plane) that appeared at 2 theta $=$ $25.7^{\circ}$. These results proved the complete conversion of GO to reduced graphene.

FT-IR measurements were also used to explore the functional groups associated with GO and graphene prepared. Figure 3 shows the IR spectrum of GO where the presence of carboxylic groups after oxidation steps was confirmed with the peaks at $1719 \mathrm{~cm}^{-1}$ and $1407 \mathrm{~cm}^{-1}$, which correspond to the stretching of $\mathrm{C}=\mathrm{O}$ (carbonyl/carboxyl) and $\mathrm{C}-\mathrm{O}$

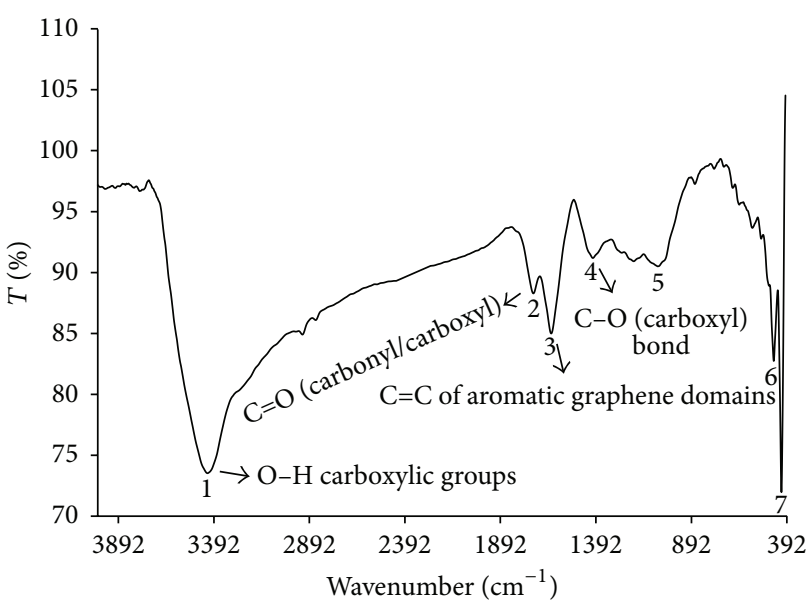

FIGURE 3: IR spectrum of graphene oxide.

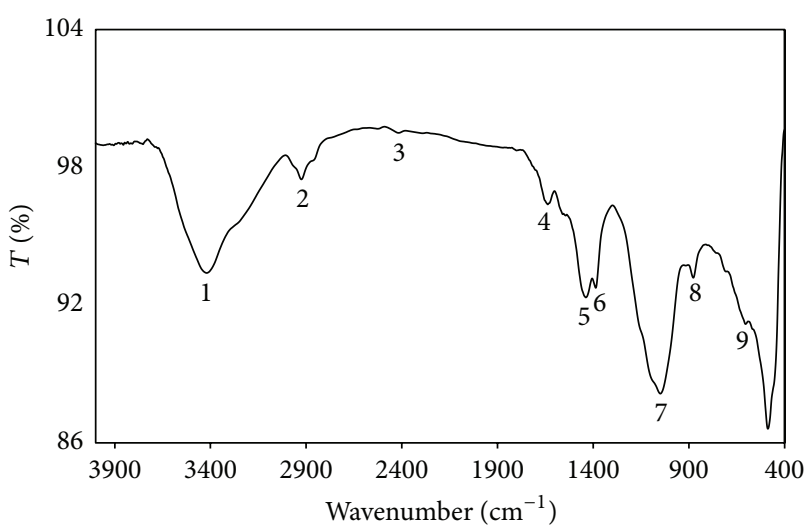

FIGURE 4: IR spectrum of graphene.

(carboxyl) bond, respectively. The broad band at $3425 \mathrm{~cm}^{-1}$ was assigned to the stretching of $\mathrm{O}-\mathrm{H}$ carboxylic groups. The stretching at $1067 \mathrm{~cm}^{-1}$ corresponds to $\mathrm{C}-\mathrm{O}$ (epoxy group). The peak at $1625 \mathrm{~cm}^{-1}$ is assigned to $\mathrm{C}=\mathrm{C}$ stretching of aromatic domains on the graphene surface. Figure 4 shows the IR spectrum of chemically prepared graphene. The IR results showed the reduction of the carboxyl groups (graphene$\mathrm{COOH}$ ) to hydroxymethyl (graphene- $\mathrm{CH}_{2} \mathrm{OH}$ ) as indicated by the disappearance of the $\mathrm{C}=\mathrm{O}$ bands $\left(\right.$ at $1719 \mathrm{~cm}^{-1}$ ) and the appearance of a band at $2925 \mathrm{~cm}^{-1}$ specific to the $\mathrm{sp}^{3} \mathrm{C}-$ $\mathrm{H}$ bond of the $\mathrm{CH}_{2} \mathrm{OH}$ group of the reduced graphene.

The fine structure and morphology of the graphene layers prepared by the reduction of GO were investigated by HRTEM microscope. Thus, Figure 5 shows representative HRTEM image of graphene sheet. Figure 5 shows that graphene sheets are represented by a very thin layer of graphene and nearly a transparent layer. The structure of graphene as depicted from Figure 5 showed well separated single layer of graphene sheets that will allow better distribution of the nanoparticles and the inclusion of 1,6-diaminohexane functionalities over the surface of the material.

3.2. Functionalization of Graphene with 1,6-Diaminohexane and Silver Nanoparticles. The surface structure and bonding 

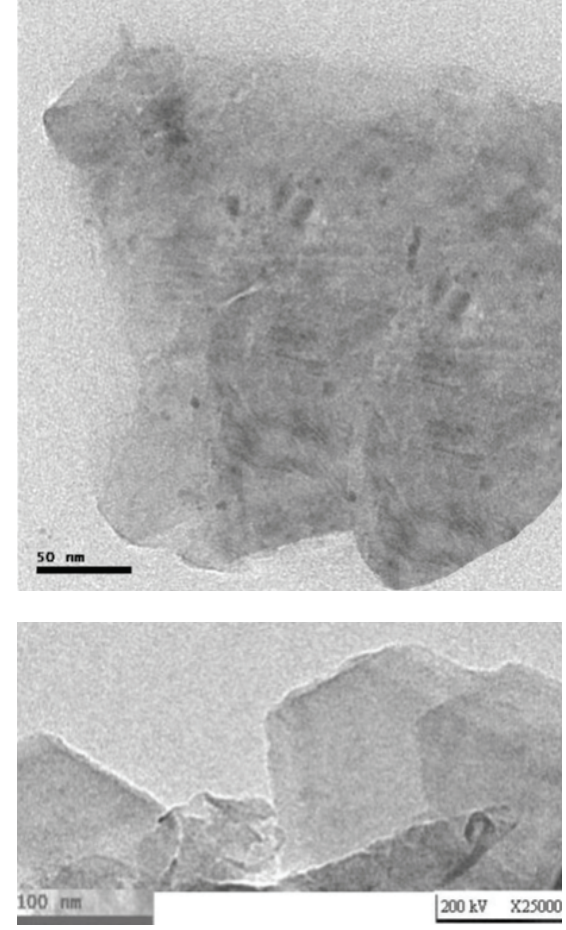

FIGURE 5: HR-TEM of graphene film.

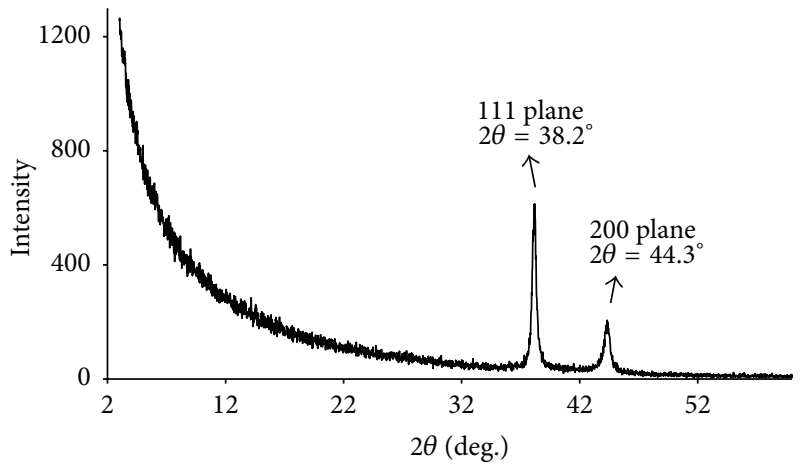

FIGURE 6: XRD pattern of graphene functionalized by 1,6-diaminohexane with silver nanoparticles.

nature of graphene functionalized by 1,6-diaminohexane with silver nanoparticles were characterized by XRD, ${ }^{1} \mathrm{HNMR}, \mathrm{IR}$, and HRTEM techniques.

Figure 6 shows the XRD pattern of graphene functionalized by 1,6-diaminohexane with silver nanoparticles where characteristic peaks $\left(111,200\right.$ planes) appear at 2 theta: $\left(38.2^{\circ}\right.$, $44.3^{\circ}$ ) indicating the formation of silver nanoparticles on the surface of the graphene functionalized by 1,6-diaminohexane.

The AgNPs were formed in a fcc crystallinity on the surface of the graphene functionalized by 1,6-diaminohexane according to the standard values.

On the other hand, Figure 7 shows FT-IR spectrum of the 1,6-diaminohexane-silver nanoparticles functionalized graphene. The two peaks with spikes at $3781 \mathrm{~cm}^{-1}$ and $3693 \mathrm{~cm}^{-1}$ representing the formation of primary amine $\mathrm{NH}_{2}$

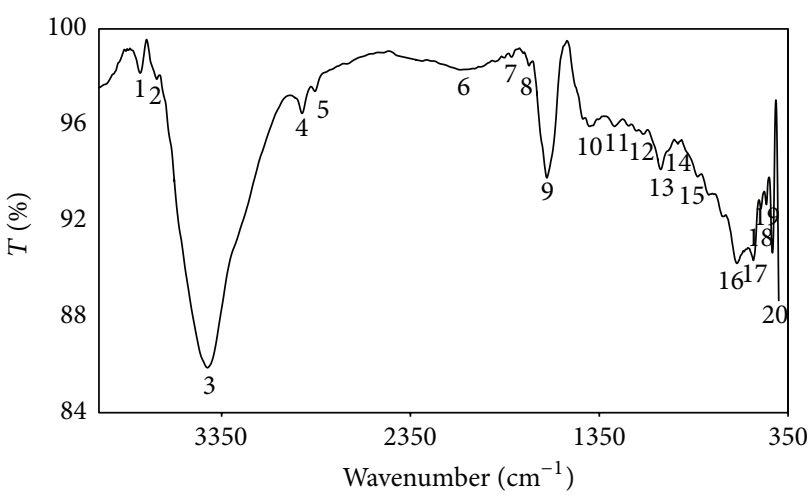

FIGURE 7: IR of graphene functionalization by 1,6-diaminohexane with silver nanoparticles.

group and the band at $1024 \mathrm{~cm}^{-1}$ corresponding to $\mathrm{C}-\mathrm{N}$ bond can be noticed in Figure 7.

${ }^{1}$ HNMR spectrum of 1,6-diaminohexane-silver nanoparticles functionalized graphene is depicted in Figure 8. The broad chemical shift at $1.5 \mathrm{ppm}$ corresponds to the protons of the primary amine group $\mathrm{NH}_{2}$ (taking symbol A) proving the functionalization of graphene by 1,6-diaminohexane. The chemical shifts at 1.26, 1.29, 1.31, 1.34, and $1.35 \mathrm{ppm}$ refer to the protons on the 2,3,4,5 carbons of $\mathrm{CH}_{2}$ group that is linked to the alkyl chain of 1,6-diaminohexane $\left(\mathrm{NH}_{2} \mathrm{CH}_{2} \mathrm{CH}_{2} \mathrm{CH}_{2}-\mathrm{CH}_{2} \mathrm{CH}_{2} \mathrm{CH}_{2} \mathrm{NH}_{2}\right.$ ) (taking symbol C). The chemical shifts at 2.48,2.50, and $2.52 \mathrm{ppm}$ are assigned to the protons on 1,6 carbons of $\mathrm{CH}_{2}$ group that is linked to $\mathrm{NH}_{2}$ and $\mathrm{CH}_{2}\left(\mathrm{NH}_{2} \mathrm{CH}_{2} \mathrm{CH}_{2} \mathrm{CH}_{2}-\mathrm{CH}_{2} \mathrm{CH}_{2} \mathrm{CH}_{2} \mathrm{NH}_{2}\right)$ (taking symbol B) ascertaining the functionalization of graphene by 1,6-diaminohexane:

\begin{tabular}{|c|c|}
\hline A $\quad$ B & B \\
\hline $\mathrm{NH}_{2}-\mathrm{CH}_{2}-($ & $\left(\mathrm{CH}_{2}\right)_{4}-\mathrm{CH}_{2}-\mathrm{NH}_{2}$ \\
\hline Type of proton & Chemical shift (ppm) \\
\hline A & 1.5 \\
\hline & 2.50 \\
\hline & 1.29 \\
\hline
\end{tabular}

The main forces stabilizing the functionalization are the hydrogen bonding between the nitrogen, oxygen, and hydrogen on the composite surface, in addition to Van der Waals forces and dipolar attractions through all the hybrid material thanks to the electron rich surface of graphene and its electrostatic attraction with the amine group and silver.

The morphology and size distribution were studied using HR-TEM. The composite films were characterized by HRTEM; the images are given in Figure 9. The silver nanoparticles can be identified to be embedded within the graphene matrix.

The figures show the HR-TEM of graphene functionalization by 1,6-diaminohexane with AgNPs where the images were taken by high magnification HRTEM. The power beam is $200 \mathrm{KV}$. The figures show the presence of a mixture of 
TABLE 1: Disinfection treatment data from Total Coliform and Fecal Coliform using 1,6-diaminohexane-silver nanoparticles functionalized graphene. Zone 1 for Bahr El-Baqar and Zone 2 for Kochainer.

\begin{tabular}{llccccc}
\hline & \multirow{2}{*}{ Parameters } & \multirow{2}{*}{ Unit } & \multicolumn{2}{c}{ Zone 1 } & \multicolumn{2}{c}{ Zone 2 } \\
& & & Sample 1 & Sample 2 & Sample 3 & Sample 4 \\
\hline \multirow{2}{*}{ Before treatment } & Total Coliform & CFU/100 mL & 5000000 & 2600000 & 3000000 \\
& Fecal Coliform & CFU/100 mL & 700000 & 500000 & 1200000 & 300000 \\
\hline \multirow{2}{*}{ After treatment } & Total Coliform & CFU/100 mL & 10 & 0 & 0 & 0 \\
& Fecal Coliform & CFU/100 mL & 3 & 0 & 0 \\
\hline
\end{tabular}

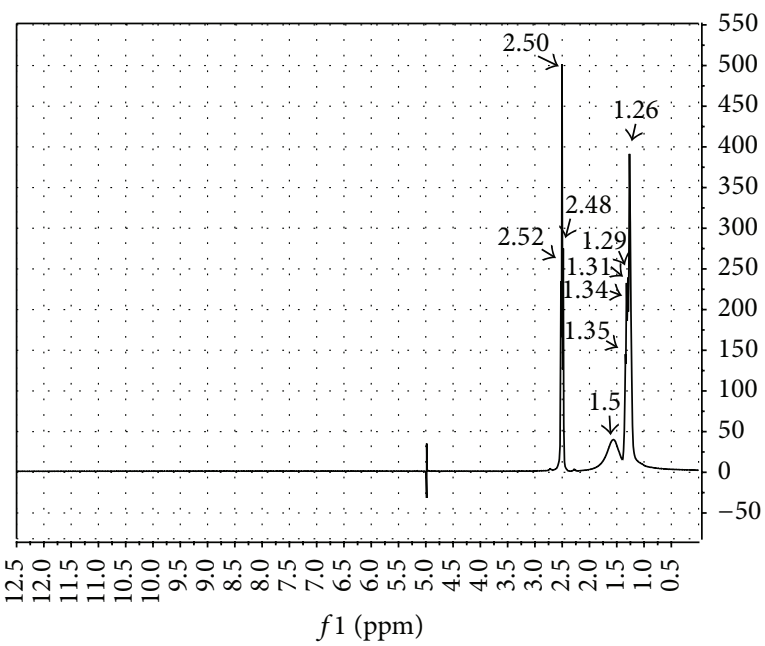

Figure 8: ${ }^{1} \mathrm{HNMR}$ of graphene functionalization by 1,6-diaminohexane with silver nanoparticles.

graphene layers. Most of the layers are bilayers or few layers of graphene on which AgNPs are deposited on its surface by different sizes.

3.3. Antibacterial Activity against Water Pathogens. The main goal of this part of the work is to explore the efficiency of the synthesized hybrid material towards antibacterial activities. Therefore, four water samples were collected according to the regular protocols for water sampling from two locations around water sewage around Bahr El-Baqar and Kotchainer regions. The results were compared to the control samples before treatment with the composite material.

First, the results of using graphene functionalized by 1,6-diaminohexane with silver nanoparticles for disinfecting water against Total Coliform and Fecal Coliform bacteria are presented.

Before treatment, the analysis showed that Total Coliforms were 5000000 and $2600000 \mathrm{CFU} / 100 \mathrm{~mL}$ for samples 1 and 2, respectively, of the first zone and 3000000 and $1200000 \mathrm{CFU} / 100 \mathrm{~mL}$ for samples 3 and 4, respectively, of the second zone, while those for Fecal Coliforms were 700000 and $500000 \mathrm{CFU} / 100 \mathrm{~mL}$ for samples 1 and 2, respectively, of the first zone and 1200000 and $300000 \mathrm{CFU} / 100 \mathrm{~mL}$ for samples 3 and 4, respectively, of the second zone.

The treatment was achieved by using 0.1 gram of the $1,6-$ diaminohexane-silver nanoparticles functionalized graphene

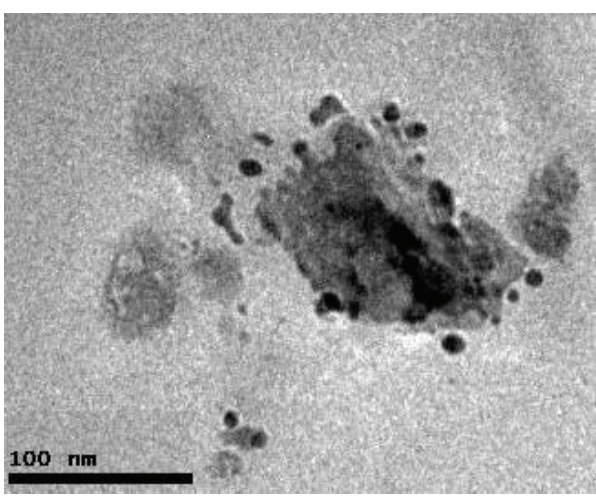

FIGURE 9: Showing the HR-TEM of graphene functionalization by 1,6-diaminohexane with AgNPs.

in $100 \mathrm{~mL}$ infected water sample. The analyses according to the protocols explained in the experimental section showed that full disinfection of all samples from Total and Fecal Coliforms was reached except the first sample where the disinfection is few colonies above zero value and about 10 and 3 colonies remain after treatment for Total and Fecal Coliform, respectively. A zero value was obtained for the other three samples as can be noticed from the data given in Table 1.

\section{Conclusions}

We synthesized successfully a new hybrid material, 1,6-diaminohexane-silver nanoparticles functionalized graphene. The synthesis followed the chemical reduction of graphene oxide that was converted to graphene. The graphene was functionalized by 1,6-diaminohexane and silver nanoparticles with different sizes. The structure of the hybrid material was ascertained from the XRD, FT-IR, and ${ }^{1}$ HNMR analyses. The morphology of the resulting hybrid contained silver nanoparticles with adequate distribution within a stack of very thin transparent graphene films composed of few layers clusters. The new material proved exceptionally effective in removing the bacterial Coliform infection of sewage water taken from some very polluted regions.

\section{Conflict of Interests}

The authors declare that there is no conflict of interests regarding the publication of this paper. 


\section{Acknowledgments}

The authors are grateful to the Environmental Research Department of the National Center for Social and Criminological Research, Egypt, and to Cairo University, Office of the Vice President for Research, for providing financial support, and to the National Water Research Center, the Nile Research Institute, for helping in bacteriology analysis and samples collection.

\section{References}

[1] S. C. Smith and D. F. Rodrigues, "Carbon-based nanomaterials for removal of chemical and biological contaminants from water: a review of mechanisms and applications," Carbon, vol. 91, no. 7, pp. 122-143, 2015.

[2] C. Tian, R. Liu, H. Liu, and J. Qu, "Disinfection by-products formation and precursors transformation during chlorination and chloramination of highly-polluted source water: significance of ammonia," Water Research, vol. 47, no. 15, pp. 5901-5910, 2013.

[3] C. M. M. Bougeard, E. H. Goslan, B. Jefferson, and S. A. Parsons, "Comparison of the disinfection by-product formation potential of treated waters exposed to chlorine and monochloramine," Water Research, vol. 44, no. 3, pp. 729-740, 2010.

[4] C. Zhu, S. Guo, Y. Zhai, and S. Dong, "Layer-by-layer selfassembly for constructing a graphene/platinum nanoparticle three-dimensional hybrid nanostructure using ionic liquid as a linker," Langmuir, vol. 26, no. 10, pp. 7614-7618, 2010.

[5] K. S. Novoselov, A. K. Geim, S. V. Morozov et al., "Electric field in atomically thin carbon films," Science, vol. 306, no. 5696, pp. 666-669, 2004.

[6] R. Hao, W. Qian, L. H. Zhang, and Y. L. Hou, "Aqueous dispersions of TCNQ-anion-stabilized graphene sheets," Chemical Communications, no. 48, pp. 6576-6578, 2008.

[7] E. Bekyarova, M. E. Itkis, P. Ramesh et al., "Chemical modification of epitaxial graphene: spontaneous grafting of aryl groups," Journal of the American Chemical Society, vol. 131, no. 4, pp. 1336-1337, 2009.

[8] L. Liu, J. Liu, Y. Wang, X. Yan, and D. D. Sun, "Facile synthesis of monodispersed silver nanoparticles on graphene oxide sheets with enhanced antibacterial activity," New Journal of Chemistry, vol. 35, no. 7, pp. 1418-1423, 2011.

[9] M. L. W. Knetsch and L. H. Koole, "New strategies in the development of antimicrobial coatings: the example of increasing usage of silver and silver nanoparticles," Polymers, vol. 3, no. 1, pp. 340-366, 2011.

[10] J. R. Morones, J. L. Elechiguerra, A. Camacho et al., "The bactericidal effect of silver nanoparticles," Nanotechnology, vol. 16, no. 10, pp. 2346-2353, 2005.

[11] C. Marambio-Jones and E. M. V. Hoek, "A review of the antibacterial effects of silver nanomaterials and potential implications for human health and the environment," Journal of Nanoparticle Research, vol. 12, no. 5, pp. 1531-1551, 2010.

[12] A. Kumar, P. K. Vemula, P. M. Ajayan, and G. John, "Silvernanoparticle-embedded antimicrobial paints based on vegetable oil," Nature Materials, vol. 7, no. 3, pp. 236-241, 2008.

[13] V. A. Oyanedel-Craver and J. A. Smith, "Sustainable colloidalsilver-impregnated ceramic filter for point-of-use water treatment," Environmental Science and Technology, vol. 42, no. 3, pp. 927-933, 2008.
[14] S. Pal, E. J. Yoon, Y. K. Tak, E. C. Choi, and J. M. Song, "Synthesis of highly antibacterial nanocrystalline trivalent silver polydiguanide," Journal of the American Chemical Society, vol. 131, no. 44, pp. 16147-16155, 2009.

[15] J. Ma, J. Zhang, Z. Xiong, Y. Yong, and X. S. Zhao, "Preparation, characterization and antibacterial properties of silver-modified graphene oxide," Journal of Materials Chemistry, vol. 21, no. 10, pp. 3350-3352, 2011.

[16] N. M. Wichner, J. Beckers, G. Rothenberg, and H. Koller, "Preventing sintering of Au and Ag nanoparticles in silica-based hybrid gels using phenyl spacer groups," Journal of Materials Chemistry, vol. 20, no. 19, pp. 3840-3847, 2010.

[17] K. J. Woo, C. K. Hye, W. K. Ki, S. Shin, H. K. So, and H. P. Yong, "Antibacterial activity and mechanism of action of the silver ion in Staphylococcus aureus and Escherichia coli," Applied and Environmental Microbiology, vol. 74, no. 7, pp. 2171-2178, 2008.

[18] Q. L. Feng, J. Wu, G. Q. Chen, F. Z. Cui, T. N. Kim, and J. O. Kim, "A mechanistic study of the antibacterial effect of silver ions on Escherichia coli and Staphylococcus aureus," Journal of Biomedical Materials Research, vol. 52, no. 4, pp. 662-668, 2000.

[19] A. B. Smetana, K. J. Klabunde, G. R. Marchin, and C. M. Sorensen, "Biocidal activity of nanocrystalline silver powders and particles," Langmuir, vol. 24, no. 14, pp. 7457-7464, 2008.

[20] S. Stankovich, D. A. Dikin, G. H. B. Dommett et al., "Graphenebased composite materials," Nature, vol. 442, no. 7100, pp. 282286, 2006.

[21] D. A. Dikin, S. Stankovich, E. J. Zimney et al., "Preparation and characterization of graphene oxide paper," Nature, vol. 448, no. 7152, pp. 457-460, 2007.

[22] W. B. Hu, C. Peng, W. J. Luo et al., "Graphene-based antibacterial paper," ACS Nano, vol. 4, no. 7, pp. 4317-4323, 2010.

[23] K. S. Kim, Y. Zhao, H. Jang et al., "Large-scale pattern growth of graphene films for stretchable transparent electrodes," Nature, vol. 457, no. 7230, pp. 706-710, 2009.

[24] S. Park and R. S. Ruoff, "Chemical methods for the production of graphenes," Nature Nanotechnology, vol. 4, no. 4, pp. 217-224, 2009.

[25] J. Liu, L. Liu, H. Bai, Y. Wang, and D. D. Sun, "Gram-scale production of graphene oxide- $\mathrm{TiO}_{2}$ nanorod composites: towards high-activity photocatalytic materials," Applied Catalysis B: Environmental, vol. 106, no. 1-2, pp. 76-82, 2011.

[26] Y.-G. Zhou, J.-J. Chen, F.-B. Wang, Z.-H. Sheng, and X.-H. $\mathrm{Xia}$, "A facile approach to the synthesis of highly electroactive Pt nanoparticles on graphene as an anode catalyst for direct methanol fuel cells," Chemical Communications, vol. 46, no. 32, pp. 5951-5953, 2010.

[27] R. Pasricha, S. Gupta, and A. K. Srivastava, "A facile and novel synthesis of Ag-graphene-based nanocomposites," Small, vol. 5, no. 20, pp. 2253-2259, 2009.

[28] I. V. Lightcap, T. H. Kosel, and P. V. Kamat, "Anchoring semiconductor and metal nanoparticles on a two-dimensional catalyst mat. storing and shuttling electrons with reduced graphene oxide," Nano Letters, vol. 10, no. 2, pp. 577-583, 2010.

[29] R. Muszynski, B. Seger, and P. V. Kamat, "Decorating graphene sheets with gold nanoparticles," The Journal of Physical Chemistry C, vol. 112, no. 14, pp. 5263-5266, 2008.

[30] J. S. Park, S. M. Cho, W.-J. Kim, J. Park, and P. J. Yoo, "Fabrication of graphene thin films based on layer-by-layer self-assembly of functionalized graphene nanosheets," ACS Applied Materials and Interfaces, vol. 3, no. 2, pp. 360-368, 2011. 
[31] C. N. R. Rao, K. Biswas, K. S. Subrahmanyam, and A. Govindaraj, "Graphene, the new nanocarbon," Journal of Materials Chemistry, vol. 19, no. 17, pp. 2457-2469, 2009.

[32] A. K. Geim and K. S. Novoselov, “The rise of graphene," Nature Materials, vol. 6, no. 3, pp. 183-191, 2007.

[33] K. S. Novoselov, D. Jiang, F. Schedin et al., "Two-dimensional atomic crystals," Proceedings of the National Academy of Sciences of the United States of America, vol. 102, no. 30, pp. 10451-10453, 2005.

[34] P. R. Somani, S. P. Somani, and M. Umeno, "Planer nanographenes from camphor by CVD," Chemical Physics Letters, vol. 430, no. 1-3, pp. 56-59, 2006.

[35] A. Reina, X. Jia, J. Ho et al., "Large area, few-layer graphene films on arbitrary substrates by chemical vapor deposition," Nano Letters, vol. 9, no. 1, pp. 30-35, 2009.

[36] V. C. Tung, M. J. Allen, Y. Yang, and R. B. Kaner, "Highthroughput solution processing of large-scale graphene," Nature Nanotechnology, vol. 4, no. 1, pp. 25-29, 2009.

[37] S. Stankovich, D. A. Dikin, R. D. Piner et al., "Synthesis of graphene-based nanosheets via chemical reduction of exfoliated graphite oxide," Carbon, vol. 45, no. 7, pp. 1558-1565, 2007.

[38] J. H. Lee, D. W. Shin, V. G. Makotchenko et al., "One-step exfoliation synthesis of easily soluble graphite and transparent conducting graphene sheets," Advanced Materials, vol. 21, no. 43, pp. 4383-4387, 2009.

[39] D. Li, W. Windl, and N. P. Padture, "Toward site-specific stamping of graphene," Advanced Materials, vol. 21, no. 12, pp. 1243-1246, 2009.

[40] D. V. Kosynkin, A. L. Higginbotham, A. Sinitskii et al., "Longitudinal unzipping of carbon nanotubes to form graphene nanoribbons," Nature, vol. 458, no. 7240, pp. 872-876, 2009.

[41] L. Y. Jiao, L. Zhang, X. R. Wang, G. Diankov, and H. J. Dai, "Narrow graphene nanoribbons from carbon nanotubes," Nature, vol. 458, no. 7240, pp. 877-880, 2009.

[42] Y. Si and E. T. Samulski, "Synthesis of water soluble graphene," Nano Letters, vol. 8, no. 6, pp. 1679-1682, 2008.

[43] W. Guoxiu, Y. Juan, P. Jinsoo et al., "Facile synthesis and characterization of graphene nanosheets," Journal of Physical Chemistry C, vol. 112, no. 22, pp. 8192-8195, 2008.

[44] R. Muszynski, B. Seger, and P. V. Kamat, "Decorating graphene sheets with gold nanoparticles," Journal of Physical Chemistry C, vol. 112, no. 14, pp. 5263-5266, 2008.

[45] H. C. Schniepp, J.-L. Li, M. J. McAllister et al., "Functionalized single graphene sheets derived from splitting graphite oxide," The Journal of Physical Chemistry B, vol. 110, no. 17, pp. 85358539, 2006.

[46] M. J. McAllister, J.-L. Li, D. H. Adamson et al., "Single sheet functionalized graphene by oxidation and thermal expansion of graphite," Chemistry of Materials, vol. 19, no. 18, pp. 4396-4404, 2007.

[47] G. Williams, B. Seger, and P. V. Kamt, " $\mathrm{TiO}_{2}$-graphene nanocomposites. UV-assisted photocatalytic reduction of graphene oxide," ACS Nano, vol. 2, no. 7, pp. 1487-1491, 2008.

[48] A. B. Bourlinos, D. Gournis, D. Petridis, T. Szabó, A. Szeri, and I. Dékány, "Graphite oxide: chemical reduction to graphite and surface modification with primary aliphatic amines and amino acids," Langmuir, vol. 19, no. 15, pp. 6050-6055, 2003.

[49] T. A. Pham, B. C. Choi, K. T. Lim, and Y. T. Jeong, "A simple approach for immobilization of gold nanoparticles on graphene oxide sheets by covalent bonding," Applied Surface Science, vol. 257, no. 8, pp. 3350-3357, 2011. 

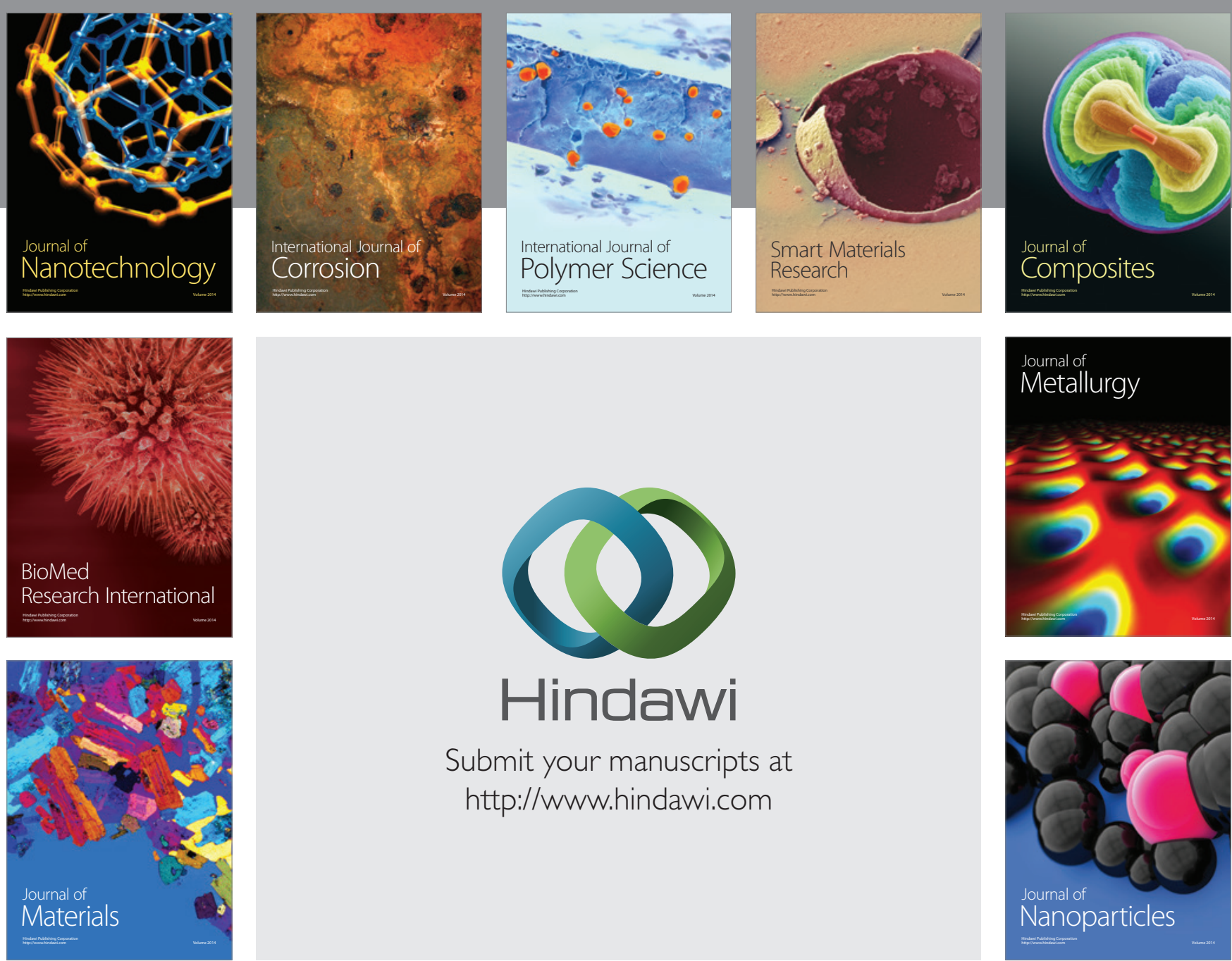

\section{Hindawi}

Submit your manuscripts at

http://www.hindawi.com

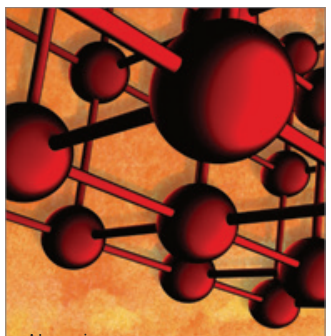

Materials Science and Engineering
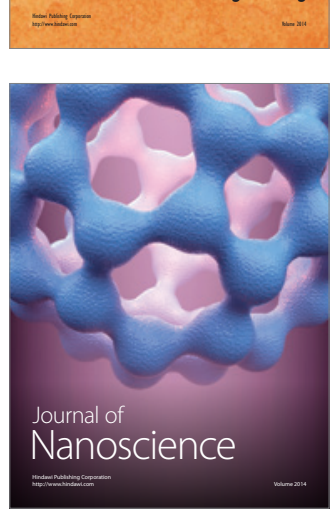
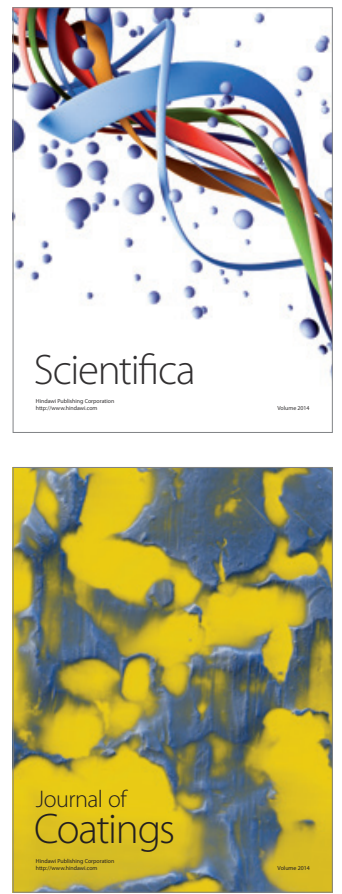
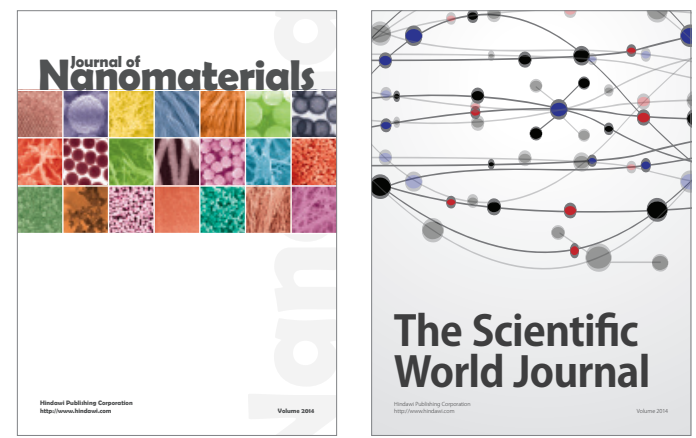

The Scientific World Journal
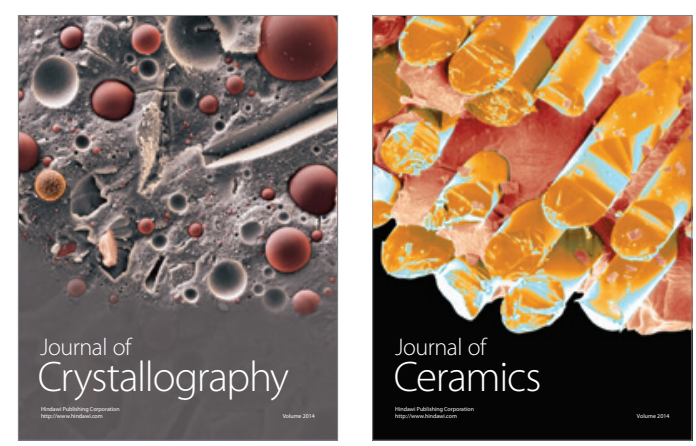
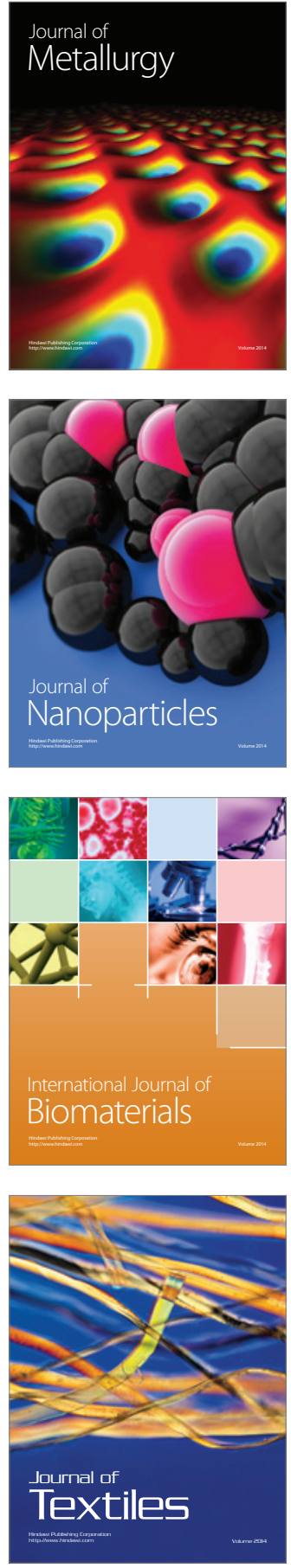